\title{
KNOWLEDGE AND ATTITUDE OF INTERNS IN REPORTING AND EVALUATING SEXUAL ABUSE
}

KEY WORDS:

\section{Dr. Unmesh.A.I \\ Dr. Bindhu \\ Vasudevan.*}

\section{Bahuleyan}

Dr. Biju

Additional Professor of Forensic Medicine Govt. Medical College, Ernakulam.

Additional Professor of Community Medicine Govt. Medical College, Ernakulam. *Corresponding Author.

INTRODUCTION: Every year the crime rate reported against women has been on the rise but the conviction rate of offenders was found to be below $30 \%$.This could be due to the lack of evidences against the perpetrators. Young medical graduates or interns are the first point of contact in any sexual abuse cases and the onus of collecting evidence depends on their knowledge and attitude. The present study was designed based on this back drop. METHODOLOGY: after obtaining ethics committee clearance 91 interns were recruited for the study. The data was collected using a validated questionnaire comprising of 20 questions related to knowledge and 10 questions about attitude. Based on the scores obtained they were categorised into three groups of poor, average and good knowledge. Analysis between knowledge level and gender of interns was done using chi-square test and difference in knowledge score of males and females was tested using independent sample $t$ test.

RESULTS: Of the 91 male interns $75 \%$ of males and $62.7 \%$ of females had good knowledge but this was not statistically significant. Significant difference in the attitude of male and female interns was noted.

CONCLUSION: Lack of knowledge in cases of sexual abuse can result in escape of the perpetrators of this heinous crime. The training of interns regarding medicolegal aspects should be made mandatory. Further the medical students also need to be exposed to these legal aspects as a part of their training program.

\section{INTRODUCTION:}

Sexual abuse is termed as the commonest evils of today's society. It plagues our nation and all members of our society, regardless of the age, sex, social standing or religion are vulnerable to this crime. It has a devastating effect on both physical and emotional health of the victim (1). By definition, sexual abuse also referred to as molestation, is usually undesired sexual behaviour by one person upon another. In the year 2019 there were 405861 cases of crime against women, showing an increase of $7.3 \%$ over $2018.7 .9 \%$ cases of rape and $21.8 \%$ cases of insult to modesty of women were reported from all over India (2). Among the rape cases reported one third of the victims were minor girls. But these reported cases are only the tip of the iceberg. A proper statistics on the number of sexual assault cases and the conviction rate of rape offenders are not available. Shock, fear and disbelief are the immediate effect of sexual abuse followed by anxiety, fear or post traumatic disorders. The survivors of sexual assault deserve Competent and compassionate survivor centred care.

Doctors as professionals have a distinct and complementary role in responding to sexual assault. A timely and high quality medical examination is needed to address sexual assault survivor's concerns, to minimize trauma and to promote healing (3). Doctors become involved when they have to report suspected abuse or when they have to medically evaluate a person who is an alleged victim of abuse. Due to the ethereal nature of evidences in sexual assault cases the medical examination plays paramount importance. This examination helps in proper evidence collection which can aid in criminal investigation hence make the perpetrators accountable for the horrendous crime committed by them (4).

Variability regarding who can conduct an inspection of the survivor and the manner in which these cases are referred are all areas where no protocols have been established and if protocols are present medical graduates are not aware of these. Some situations pose ethical dilemma for doctors which cannot be resolved easily. Knowledge about what |www.worldwidejournals.com constitutes sexual abuse, neglect or maltreatment and a properly designed protocol for examination of the same would decrease the burden for doctors and further ensure that the survivors of sexual abuse is benefitted. The decision making of 'to report or not to report a case of suspected sexual abuse' is difficult but it does not negate the doctor's professional and legal responsibility towards the survivor (5). The doctor is not responsible for determining whether abuse occurred, only for reporting reasonable suspicion. To enable the sexual assault victims to open up more about their trauma and communicate their health care concerns, the patient physician interactions need to generate trust in the victims (6).

Being the first safe contact in majority of sexual assault cases lack of proper examination would result in total injustice to the survivor. Often incomplete records and unnecessary comments are misused by the law enforcing agencies as well as the defence party resulting in secondary victimization of the survivor resulting in compounding the psychosocial impact of the event. Lack of knowledge regarding the legal and medical procedures related to reporting and evaluating a case of sexual abuse would result in not only denial of justice to the victim but the doctor himself unknowingly might cause harm to his own career. Hence it is important to understand the level of training that each medical graduate has received in this respect. The knowledge and attitude of the medical graduates with regards to sexual abuse thus becomes of prime importance in the present scenario. The prime focus of the present study is to estimate the knowledge of interns regarding the recent updates related to the clinical practice and medico legal proceedings when examining a sexual assault survivor. The attitudes of the interns are also being explored.

\section{MATERIALS AND METHODS:}

This descriptive cross sectional study was conducted in Government Medical College, Ernakulam after obtaining clearance from the Institutional Ethics Committee. The students who had passed the final MBBS exams were taken as the study participants. After obtaining consent from the study 
participants the data was collected during the orientation sessions for interns. Data collection was done using a validated questionnaire which had twenty questions with true or false response and ten questions were allotted to assess the attitude. Each correct response to the knowledge question was scored as one hence the total score obtained would be twenty. Based on the scores obtained the respondents were categorised as having poor knowledge when score was less than 6, average knowledge when score is between 7-13 and good knowledge if score is above 14.the knowledge questions were further grouped into two components, questions related to practices during examination of a sexual assault survivor and questions related to recent legal updates related to sexual abuse. Attitude was measured using the 5 point Likert scale.

\section{STATISTICS:}

Data was coded and entered in Microsoft Excel software and analysis was done using SPSS software version 22.Qualitative variables such as age group, gender, knowledge and attitude regarding various aspects of sexual abuse was summarised using frequency and percentage .Data regarding knowledge score was found to be normally distributed as depicted by Q$\mathrm{Q}$ plot for normality. So Mean, standard deviation and $95 \%$ confidence interval of knowledge score was calculated. Analysis between knowledge level and gender of interns was done using chi-square test and difference in knowledge score of males and females was tested using independent sample $t$ test. Significance level was fixed at a $p$ value $<0.05$

\section{RESULTS:}

of the total 91 interns 32 were males and 59 were females. In both group of interns all had knowledge scores above six hence there were no respondents belonging to the poor knowledge group. Mean knowledge score of the interns was $14 \pm 2.2$ (95\% Confidence interval 13.59- 14.49).

Of the 91 male interns $75 \%$ of males and $62.7 \%$ of females had good knowledge. The association between the gender and knowledge level was not statistically significant. Similarly there was no significant difference in the mean knowledge score of males and females regarding sexual abuse.......(14.2 \pm 2.1 vs $13.9 \pm 2.1$; t value $0.56 ;$ p value 0.57 ).

Table: 1. Knowledge of interns in reporting and evaluating sexual abuse.

\begin{tabular}{|l|l|l|l|l|}
\hline Interns & $\begin{array}{l}\text { Knowledge } \\
\text { average }\end{array}$ & Good & Total & P value \\
\cline { 1 - 4 } Male & $7(21.9 \%)$ & $25(75 \%)$ & 32 & \multirow{2}{*}{0.132} \\
\cline { 1 - 3 } & $22(37.3 \%)$ & $37(62.7 \%)$ & 59 & \\
\hline Total & 29 & 62 & 91 & \\
\hline
\end{tabular}

Figure: 1. Knowledge Of Interns About Recent Legal Updates Related To Sexual Abuse

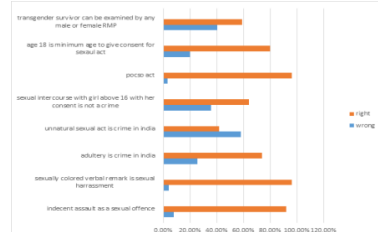

Figure: 2. Knowledge Of Interns Regarding Practices Related To Examination Of Sexual Abuse Survivors.

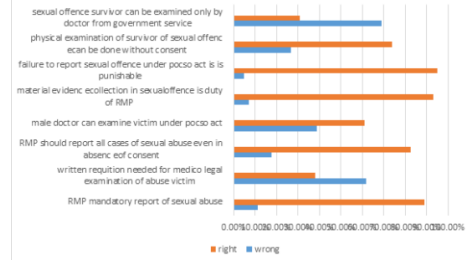

FIGURE: 3. ATTITUDE OF MALE INTERNS REGARDING SEXUAL ABUSE.

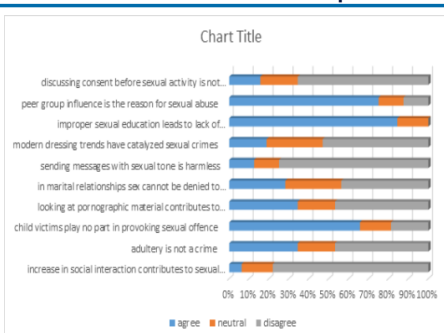

Figure: 4. Attitude Of Female Interns Regarding Sexual Abuse.

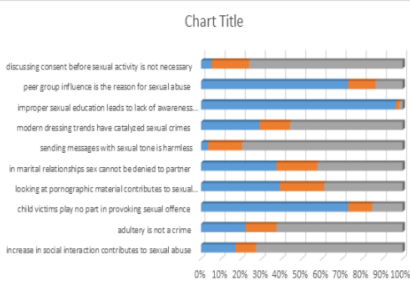

DISCUSSION:

Ignorantia juris non excusat or ignorantia legis neminem excusat(Latin for 'ignorance of the law excuses not' and 'ignorance of law excuses no one' respectively is a legal principle holding that a person who is unaware of a law may not escape liability for violating that law by merely because one was unaware of its content $(7,8)$. The numbers of litigation cases against doctors are on the rise and in examining a case of sexual abuse lack of awareness ends in loss of crucial evidences which can culminate in damage to the survivor and escape of the perpetrator. Lack of competence of medical professionals often negatively impacts on the integrity of medico legal evidences as noted by Du Mont andWhite (9).

In the present study it was found that $75 \%$ of males and $62.7 \%$ of females had good knowledge regarding medico legal procedures related to sexual abuse. But this difference in knowledge among interns was not found to be statistically significant. There was no intern with poor knowledge regarding sexual abuse. The present study shows that most of the interns were aware of the basic legal rules but many do not have exposure to the recent changes with regards to laws related to sexual abuse.

Of the questions related to legal updates it was found that around $57.9 \%$ of interns were unaware that unnatural sexual act is no longer considered as a crime in India. About $40 \%$ of interns were not aware that a transgender survivor of sexual offence has the right to choose whether they can be examined by a male or female registered medical practitioner. The age of individual for giving sexual consent has been modified from 16 to 18 years and $36 \%$ of interns were not aware of this fact. $25 \%$ of interns were not aware of the new regulation where adultery is not considered as a crime. The positive findings in the study is that around $97 \%$ of interns were well aware of the pocso act and what amounts to sexual harassment and indecent assault. $69 \%$ of interns had the wrong opinion that sexual offence survivor can be examined only by a doctor under government service. $62 \%$ is not aware that a written requisition from police is not needed for the medico legal examination of the sexual offence survivor.

The attitude of male and female interns regarding sexual abuse was explored into. Though the Indian law has modified the law as "adultery is not a crime" it was found that $46.9 \%$ of males and $62.7 \%$ of females interns are of the opinion that adultery is a crime. $39 \%$ of females and $34 \%$ of males believe that watching pornographic materials can lead on to sexual crimes. With regard to their opinion in relation to marital sex $43.8 \%$ of males opined that sex can be denied to partners while $22 \%$ of the females were of the opposite opinion. $28.8 \%$ 
of females believe that modern dressing trends leads on to sexual abuse. Both male and female interns agree to the fact that lack of proper sex education leads to decreased sexual awareness in youngsters. This perspective regarding importance of sex education was highlighted in a Rape myth acceptance (RMA) survey done among university students and it was found that males has higher RMA scores and lesser the sexual education more the acceptance $(10,11)$.

\section{CONCLUSION:}

Interns are often the first point of contact in any medical college setting and in cases of sexual abuse an intern is expected to competently and empathetically handle the situation. Lack of awareness of the medico legal updates related to sexual abuse can result in failure to document details and accidently tampering evidence. As a student, training is imparted related to sexual abuse only during their forensic medicine classes and this is not reinforced. Hence an intern will not be aware of the recent changes incorporated. Further the interns have only been exposed to theoretical aspects of forensic medicine. Competency of the intern in dealing with sexual assault cases can be ensured only by incorporating effective training in clinical forensic medicine during different phases of their course.

\section{REFERENCES:}

1. Kems DL, Terman DL, Larson CS: Role of physicians in reporting and evaluating child sexual abuse. Future child 1994;4(2):119-34.

2. National Crime Records Bureau, Ministry of Home Affairs. ncrb.gov.in (latest updated on 16.11.2020)

3. Clare Dyer. Every doctor has a duty to report suspected child abuse or neglect. BM] 2012;345:4719.

4. Lalitha D'souza. Sexual assault: The role of the examining doctor. Issues in medical ethics 1998;6(4):113-116.

5. Putnam FW.Ten year research updates review: Child sexual abuse. Journal of the american academy of child and adolescent psychiatry. 2003; 42(3): 26978.

6. Wolak J, Finkelhor D, Mitchell KJ, Ybarra ML. Online 'predators' and their victims: myths, realities and implications for prevention and treatment. The American psychologist 2008;63(2): 111-28.

7. Black's law dictionary, 5 th edition, page 672.

8. Black's law dictionary, 5th edition, page 673.

9. Du Mont J, White D. Barriers to the effective use of medico-legal findings in sexual assault cases worldwide. Qual Health Res. 2013; doi: sexual assault cases worldwide. Q
10.1049732313502396 . [Web of Science ${ }^{\circledR}$ ]

10. Braiding. M.J, Smith S.G, Basil. K.C, Walters. M.L, Chen, J, \& Merrick, M. T. (2014). Prevalence and characteristics of sexual violence, stalking, and intimate partner violence victimization - National intimate partner and sexual violence survey, United States, 2011. Morbidity and Mortality Weekly Report, 63, 1-18.

11. Aronowitz, T., Lambert, C. A., \& Davidoff, S. (2012). The role of rape myth acceptance in the social norms regarding sexual behaviour among college students. Journal of Community Health Nursing, 29(3), 173-182. 